\title{
A Simplified Formula for the Determination of the Fundamental Period of Mixed Structures with Vertical Combination of Different Seismic Resisting Systems
}

\author{
Amir Saadatkhah \\ Sahand University of Technology \\ Mohammad Reza Chenaghlou \\ Sahand University of Technology \\ Mehdi Poursha ( $\nabla$ poursha@sut.ac.ir) \\ Sahand University of Technology https://orcid.org/0000-0002-6307-562X
}

\section{Research Article}

Keywords: Simplified formula, the fundamental period, mixed buildings, Rayleigh's method, vertical combination of different systems

Posted Date: January 3rd, 2022

DOI: https://doi.org/10.21203/rs.3.rs-1182989/v1

License: (c) (1) This work is licensed under a Creative Commons Attribution 4.0 International License.

Read Full License 


\title{
A Simplified Formula for the Determination of the Fundamental Period of Mixed Structures with Vertical Combination of Different Seismic Resisting
}

Systems

\author{
Amir Saadatkhah ${ }^{1}$, Mohammad Reza Chenaghlou ${ }^{2}$ and Mehdi Poursha ${ }^{3}$
}

\begin{abstract}
Vertical combination of different seismic resisting systems, permitted in the seismic design codes such as ASCE/SEI 7-16, is an effective choice for the structural design of mid- and high-rise buildings. In the seismic analysis of structures, according to the seismic codes, an estimate of the fundamental period of vibration is needed. On other hand, there is no simplified equation to compute the fundamental period of vibration of mixed buildings with vertical combination of different seismic resisting systems. In this study, by using the Rayleigh's method, a simplified equation for determining the fundamental period of this type of structures is proposed. This equation is verified by the eigenvalue analysis of the mathematical model of the 11 building frames with different seismic characteristics along their height. Furthermore, two different mixed structures composed of steel and reinforced concrete moment resisting frame (MRF) structures as well as of steel (concentrically braced frame) $\mathrm{CBF}$ and reinforced concrete MRF structures are examined in this paper. The results indicate that the proposed formula results in the fundamental period of mixed structures with satisfactory accuracy. The largest and average errors in the fundamental period of the

\footnotetext{
${ }^{1}$ PhD Candidate, Faculty of Civil Engineering, Sahand University of Technology, Tabriz. Iran.

${ }^{2}$ Professor, Faculty of Civil Engineering, Sahand University of Technology, Tabriz, Iran.

${ }^{3}$ Associate Professor, Faculty of Civil Engineering, Sahand University of Technology, Tabriz, Iran (corresponding author).E-mail: Poursha@sut.ac.ir
} 
buildings under consideration, obtained by the proposed formula, are less than $10 \%$ and $6 \%$, respectively, compared to the eigenvalue analysis.

Keywords Simplified formula; the fundamental period; mixed buildings; Rayleigh's method; vertical combination of different systems.

\section{Introduction}

Modern urban design causes engineers to face with a new challenge which is the vertical combination of different seismic resisting systems that is permitted in the seismic codes. The most important reasons for such a combination of different seismic resisting systems are:

- Special architectural design: For this reason, the structural engineer has to utilize such a vertical combination of different seismic resisting systems.

- Different application of stories: For instance, residential and commercial buildings are mixed together in which the lower structure requires open spaces because of the existence of retail stores or parking garages, and for that, using a different seismic resisting system from what the upper structure utilizes is the best choice.

- Lightweight construction: This process is common in high and mid-rise buildings construction. For example, a wooden structure is constructed on a concrete structure.

- Economic and construction reasons: Prefabricated structures are sometimes needed at the upper stories in which the seismic resisting system can be different.

For the seismic analysis of building structures, seismic codes recommend a simplified method, i.e. the equivalent static procedure. If the simplified process is selected for the seismic analysis of a building, first of all, its fundamental period of vibration should be determined that depends on the mass and the stiffness of the structure. 
In ASCE/SEI 41-06 (2017), ASCE/SEI 7-16 (2017), ATC3-06 (1978), Eurocode 8 (2004), IBC (2020), NBCC (2015), NEHRP (2015), and UBC (1997) the use of the Linear Static Procedure is permitted and for that, all of them have recommended some empirical equations for determining a lower bound of the fundamental period of vibration of building frames.

Goel and Chopra (1997) investigated the fundamental vibration period of 27 reinforced concrete (RC) moment resisting frame (MRF) buildings and 42 steel MRF buildings that the data were available from the instrumented buildings during the previous earthquakes. They recommended, conservatively, two formulae for estimating the period of $\mathrm{RC}$ and steel buildings. Tremblay (2005) proposed a simple expression for the fundamental period of vibration of steel concentrically braced frames located in moderate and low seismic regions for developing the National Building Code of Canada (NBCC 1995) and stated that the buildings period varies significantly with seismic hazard levels and soil conditions. Nassani (2014) proposed a formula for calculating the fundamental period of vibration of structures and took into account the effect of the semi-rigid connections, mass and the stiffness of the structure.

Lee et al. (2000) carried out full-scale measurements on $50 \mathrm{RC}$ apartment buildings and calculated the fundamental period of vibration of structures and recommended experimental formula by regression analysis on the basis of the measured period data. They concluded that the code formulae are not sufficient for estimating the fundamental period of apartment buildings with shear-wall dominant systems, representative of typical residential buildings in South-East Asia. Crowley and Pinho (2006) had an assessment about existing RC buildings and recommended a simplified equation relating the yield period of vibration of existing buildings to their height. In another investigation, Crowley and Pinho (2010) also assessed the Eurocode 8 formulae for determining the fundamental period of vibration and for using them in linear seismic analysis. They made some suggestions for the process of the 
estimation of the fundamental period of vibration in Eurocode 8. Kuşyılmaz and Topkaya (2014), by using the Rayleigh's method as a basis and the roof drift ratio (RDR) under seismic forces as a parameter, described the formulation of a hand method to estimate the computed fundamental periods of vibration of steel eccentrically braced frames. They used regression analyses to obtain such simplified equations. Kown and Kim (2010) assessed the formulae of the determination of the fundamental period of vibration of structures in ASCE 7-05 for steel and RC moment-resisting frames, shear wall buildings, braced frames, and other structural types. They obtained the differences between the periods from the code formulae and the measured periods and made some suggestions to improve the period estimated by the code formulae. Barghi and Azadbakht (2011) proposed a new formula for steel moment resisting frames by using the finite element analysis and concluded that the infills effect on the fundamental period of steel moment-resisting frames should be considered.

Panagiotis et al. (2015), by means of the finite element macro-modeling and modal eigenvalue analysis, investigated the influence of geometry and mechanical characteristics of the frames on the fundamental period of RC buildings and took into account the length and the number of spans as well as the infill masonry panel stiffness. They found that the equations of Eurocode 8 do not take into account the influence of these characteristics in computing the fundamental period of RC buildings. Therefore, the fundamental period estimated by means of the code's formula is inaccurate. Hatzigeorgiou and Kanapitsas (2013) examined 20 different real building configurations and considered the flexibility of soil and the presence of external and internal infill walls. They recommended an empirical formula for estimating the fundamental period of reinforced concrete structures by using the nonlinear regression analysis. Günaydın and Topkaya (2013) investigated the fundamental period of concentrically braced frames (CBFs) designed according to Eurocode 8 (2004) and evaluated 
the lower bound period of the frames specified by EC8 and the National Building Code of Canada (NBCC 1995). They concluded that these codes present over conservative estimates of the lower bound periods, in most cases. Furthermore, to predict the fundamental natural period of CBFs that were designed in accordance with Eurocode 8, they proposed a simple hand method by using the Rayleigh's method and taking into account the inelastic top story drift ratio as a parameter for quantifying the stiffness characteristics. Kaplan et al. (2021) stated that the codes' simplified empirical equations should be region-specific and should represent the general design and the construction characteristics of the region. They proposed a simple equation to estimate the elastic fundamental period of mid-rise $\mathrm{RC}$ buildings and compared it to the equation defined in the Turkey Building Earthquake Code (TBEC-2018). They concluded that the code's empirical equation leads to unconservative base shear values. They also investigated the influence of infill walls on the lateral stiffness of the buildings and made some preliminary suggestions.

Sveral researchers (Alguhane et al. 2016; Navarro et al. 2007; Gallipoli et al. 2008; Guler et al. 2008; Michel et al. 2010; Navarro et al. 2007; Oliveira and Navarro 2010; Ditommaso et al. 2013; Pan et al. 2014; Salameh et al. 2016) proposed some simplified equations with respect to the building's height by using ambient vibration measurements to determine the fundamental period of buildings.

Kwon and Kim (2010) investigated the ASCE/SEI 7-05 building period formulae for known resisting systems and concluded that these formulae, in general, predict accurately the lower bound of the fundamental period for low- to medium-rise braced frames and overestimate the fundamental natural period of shear wall buildings. Ahmed et al. (2019) determined the fundamental period of mid-rise reinforced concrete moment resisting frames by nonlinear dynamic analysis and compared the results with the period formulae in Eurocode 8, UBC 1997 and ASCE/SEI 7-16. They proposed some equations for calculating the period of 
vibration by regression analysis of the results. Amanat and Hoque (2006) assessed the effects of infill panels in RC frame buildings by using the 3D finite element modeling and modal eigenvalue analysis. They suggested some guidelines to determine the fundamental period of RC frames using rational approaches like modal analysis, and proposed to eliminate the necessity of code limits. Salama (2015), by taking into account the effect of both building height $(H)$ and the number of stories $(N)$ in the case of reinforced concrete moment-resisting frames, improved the formulae for estimating the fundamental period of vibration based on regression analysis of the available data measured from the recorded motions during eight California earthquakes. It was recommended that the value of coefficient $C_{t}$ in the current US and Egyptian building codes' formulae should be a function of the number of stories $(N)$. Young and Adeli (2014a; 2014b) stated that the ASCE/SEI 7-10 formula is highly conservative in computing the approximate period of moment-resisting frames and is unable to account for geometric irregularities of structures. They investigated the fundamental period of MRFs with different geometric irregularities and proposed some equations for the fundamental period of MRFs by considering vertical and horizontal irregularities. Ricci et al. (2011) investigated the elastic period of vibration of uncracked (tangent) and cracked infilled RC MRF buildings by means of modal analysis. They proposed simplified formulae based on regression analysis of the obtained numerical data. Sarkar et al. (2010), by using the concept of Rayleigh's method, assessed the degree of irregularity of a stepped building frame and proposed a regularity index. To estimate the fundamental period of stepped building frames, they proposed a modification to improve the codes' empirical formula. It is mentioned that the process of calculation of the regularity index in their approach is time-consuming and complicated. Georgoussis et al. (2015) proposed an approximate method for the calculation of the fundamental period of asymmetric setback multi-story buildings. They stated that this method may be found useful at the stage of the preliminary design, where decisions about the 
structural layout have to be taken prior to a full 3D dynamic analysis. It is noted that their method is complicated.

In accordance with the ASCE/SEI 41-17 (2017), the fundamental period of an existing building can be determined by using either an analytical, empirical, or approximate method. It is mentioned that the analytical and approximate methods can be used in the case of structures with vertical combination of different resisting systems. On the other hand, the analytical method is complicated and time-consuming and a simplified equation can be useful for this type of structures. To the authors' best knowledge, no simplified equation has been proposed in the seismic codes or previous research investigations to determine the fundamental period of vibration of mixed structures with vertical combination of different resisting systems. The central aim of this study is to propose a simplified and straightforward equation on the basis of the Rayleigh's method for determining the fundamental period of vibration of mixed building frames with vertical combination of different resisting systems. Two different mixed structures composed of steel and reinforced concrete MRF structures as well as of steel CBF and reinforced concrete MRF structures are examined in this paper. Furthermore, 11 mixed building frames with different seismic characteristics along their height are studied in this investigation. The fundamental period of the structures derived from the proposed formula is compared to that obtained from the eigenvalue analysis of the numerical model as a benchmark solution.

\section{A simplified equation for the determination of the fundamental period}

In this section, a simplified equation is proposed to determine the fundamental period of vibration of mixed building structures with vertical combination of different seismic resisting systems. For this purpose, it is supposed that the structure is composed of $n$ individual parts, as shown in Fig. 1. It is also assumed that the mass and stiffness of the stories in each part are 
the same. By using the Rayleigh's method, the process of the determination of the fundamental period of a mixed building is formulated in this section.

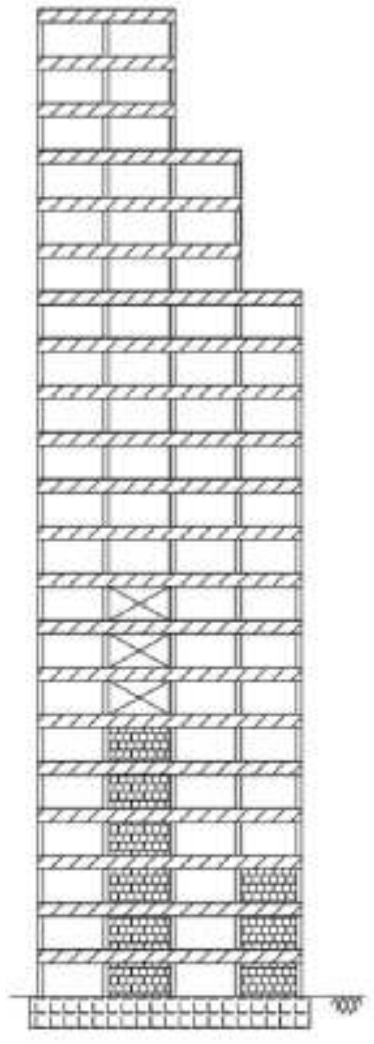

A mixed $N$-story building
A mixed structure is divided into $n$ parts based on its different seismic characteristics along the height (such as the type of seismic resisting systems, stiffness, mass, etc.)

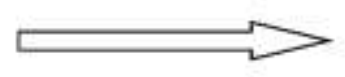

Fig. 1. Configuration of a mixed structure with vertical combination of different resisting systems.

It is worthwhile mentioning that, in some codes such as UBC (1997), the fundamental period of vibration obtained by the Rayleigh's method is formulated as follows:

$T=2 \pi \sqrt{\left(\sum_{i=1}^{n} w_{i} \Delta_{i}^{2}\right) \div\left(g \sum_{i=1}^{n} f_{i} \Delta_{i}\right)}$

where $f_{i}$ indicates any lateral force distributed approximately in accordance with any rational distribution and $w_{i}$ is portion of the total seismic load located at or assigned to level $i$. The 
elastic deflections, $\Delta_{i}$ are computed by using the applied lateral forces, $f_{i}$. This method is known as an approximate method in ASCE 41-17 (2017) and ASCE 7-16 (2016). Because the process of the determination of elastic deflections is time-consuming and complicated and the numerical modeling of the building is also needed, structural engineers are usually unwilling to use Eq. (1) in practice despite the simple appearance. To cope with this problem, a simplified method is proposed in this paper and the process is described in the following.

As illustrated in Fig. 1, first of all, an $N$-story building is divided into $n$ parts based on its different seismic characteristics along the height. Then, we have:

$\sum_{i=1}^{n} n_{i}=N$

in which $n_{i}$, is the number of stories in the $i$-th part of the building. The displacement in the foundation level, $\Delta_{0}$, is taken to be zero and other parts displacements are computed relative to the foundation.

$$
\Delta_{0}=0
$$

In the $i$-th part of the structure with $n_{i}$ stories, the mass and stiffness of each story are denoted by $m_{i}$ and $k_{i}$. The maximum displacement under inertia forces, $\Delta_{i}^{\prime}$, is calculated by neglecting the effect of the upper and lower parts as follows:

$$
\Delta_{i}^{\prime}=\frac{1+n_{i}}{2} \frac{n_{i} w_{i}}{k_{i}} \quad i=1, \ldots, n
$$


If there are upper parts on the $i$-th part of the structure, their effect on the displacement of the $i$-th part is calculated by:

$\Delta^{\prime \prime}{ }_{i}=\frac{n_{i}}{k_{i}} \sum_{j=i+1}^{n} n_{j} w_{j} \quad i=1, \ldots, n$

in which $\Delta^{\prime}{ }_{i}$ is the effect of the upper parts on the displacement of the $i$-th part. The detailed process of deriving the parameters $\Delta_{i}^{\prime}$ and $\Delta^{\prime \prime}{ }_{i}$ is presented in Appendix A. Considering the effect of the upper and lower parts (if there are any), the maximum displacement of the $i$-th part, $\Delta_{i}$, is obtained as follows:

$\Delta_{i}=\Delta_{i}^{\prime}+\Delta^{\prime \prime}+\Delta_{i-1}$

in which $\Delta_{i-1}$ is the maximum displacement of part $i-1$. Therefore, as illustrated in Fig. 1, the maximum displacement, in each part of the building under inertia forces is calculated by the following formulae:

$\Delta_{1}=\frac{1+n_{1}}{2} \frac{n_{1} w_{1}}{k_{1}}+\frac{n_{1}}{k_{1}} \sum_{j=2}^{n} n_{j} w_{j}$

$\Delta_{2}=\frac{1+n_{2}}{2} \frac{n_{2} w_{2}}{k_{2}}+\frac{n_{2}}{k_{2}} \sum_{j=3}^{n} n_{j} w_{j}+\Delta_{1}$

$\Delta_{i}=\frac{1+n_{i}}{2} \frac{n_{i} w_{i}}{k_{i}}+\frac{n_{i}}{k_{i}} \sum_{j=i+1}^{n} n_{j} w_{j}+\Delta_{i-1} \quad i=1, \ldots, n-1$

$\Delta_{n}=\frac{1+n_{n}}{2} \frac{n_{n} w_{n}}{k_{n}}+\Delta_{(n-1)}$ 
Finally, this procedure is summarized into the following form:

$$
\left\{\begin{array}{l}
\Delta_{0}=0 \\
\Delta_{i}=\frac{1+n_{i}}{2} \frac{n_{i} w_{i}}{k_{i}}+\frac{n_{i}}{k_{i}} \sum_{j=i+1}^{n} n_{j} w_{j}+\Delta_{i-1} \\
\Delta_{n}=\frac{1+n_{n}}{2} \frac{n_{n} w_{n}}{k_{n}}+\Delta_{(n-1)}
\end{array} \quad i=1, \ldots, n-1\right.
$$

in which $w_{i}$ and $k_{i}$ are the weight and stiffness of each story in the $i$-th part of the building, respectively.

The maximum potential energy, $E_{p(\max )}$, and maximum kinetic energy, $E_{k(\max )}$, of the structure, are determined by Eqs. (4) and (5), respectively:

$$
\begin{aligned}
& E_{p(\max )}=\frac{1}{2} g \sum_{i=1}^{n}\left(m_{i} \Delta_{i}\right) \\
& E_{k(\max )}=\frac{1}{2} \omega^{2} \sum_{i=1}^{n} m_{i} \Delta_{i}^{2}
\end{aligned}
$$

in which $m_{i}$ is the mass of each story in the $i$-th part of the building.

By using the Rayleigh's method which is based on the principle of energy conservation for a conservative system, it can be concluded that $E_{p(\max )}=E_{k(\max )}$ (Paultre 2011). By means of this outcome, a simplified expression for the natural frequency of a mixed structure with different seismic characteristics along the height is determined as follows:

$\omega^{2}=g \frac{\sum_{i=1}^{n} m_{i} \Delta_{i}}{\sum_{i}^{n} m_{i} \Delta_{i}^{2}}$

in which $\omega$ is the fundamental frequency of the structure in radians per second. A step-bystep flowchart of the proposed method for the calculation of the fundamental frequency of a 
mixed structure is presented in Fig. 2. Eq. (6) indicates that the displacements can be computed easily for a mixed building with vertical combination of different seismic resisting systems by using Eq. (3) in which all of the parameters are known for an existing building or can be formerly estimated for a new building structure. Therefore, the proposed formula does not need numerical modeling of the building to obtain the displacements that is cumbersome and time-consuming. This is the main advantage of the proposed formula compared to Eq. (1) suggested in UBC (1997), ASCE 41-17 (2017) and ASCE7-16 (2016).

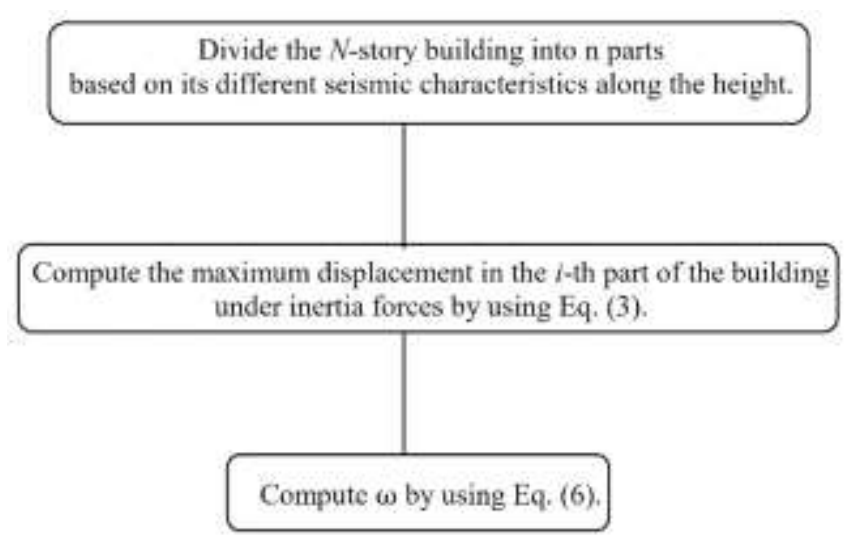

Fig. 2. Flowchart of the proposed method for determining the fundamental frequency of a mixed structure.

\section{Verification of the proposed formula}

In this section, in order to verify the proposed formula in computing the fundamental period of mixed buildings with a combination of different seismic resisting systems along the height, a large number of examples are studied. First, two different mixed structures composed of steel and reinforced concrete MRF structures as well as of steel CBF and reinforced concrete MRF structures are examined. Furthermore, 11 building frames with different seismic characteristics along the height are studied. For the verification purpose of the proposed method, the fundamental period of the structures derived from Eq. (6) is compared to that resulting from the eigenvalue analysis of the numerical model of the structures. 


\subsection{A mixed 2-story building composed of MRF steel and concrete structures}

In the first example, it is assumed that a one-story MRF steel structure is constructed on a one-story MRF concrete structure as shown in Fig. 3. Axial and shear deformation of the beams and columns, and the influence of axial force on the stiffness of the columns are ignored (Chopra 2012). The characteristics of the lower and upper parts of the structure are given in Table 1. The fundamental period and frequency of the mixed structure obtained by the proposed formula and eigenvalue analysis of the numerical model and the parameters needed in the calculation process are presented in Table 2. Each story stiffness, $k$, is calculated by the following formula [46]:

$k=\frac{24 E I_{c}}{H^{3}} \frac{12 \rho+1}{12 \rho+4}$

in which

$\rho=\frac{\left(\frac{I}{L}\right)_{b}}{2(I / L)_{c}}$

in which $E$ is the modulus of elasticity; $I_{c}$ and $I_{b}$ are the moment of inertia of the column and beam members about the flexural axis, respectively; $H$ is the height of the column and $L$ is the length of the member.

Table 2 demonstrates that the proposed formula can accurately compute the fundamental period of the mixed 2-story building and the error in the fundamental period obtained by the proposed formula is equal to $2.184 \%$, in comparison with the eigenvalue analysis of the numerical model. It is noted that, in Table $2, T_{c}$ and $T_{\text {num }}$ imply the fundamental period of the mixed structure obtained by the proposed formula and the numerical solution, respectively. 


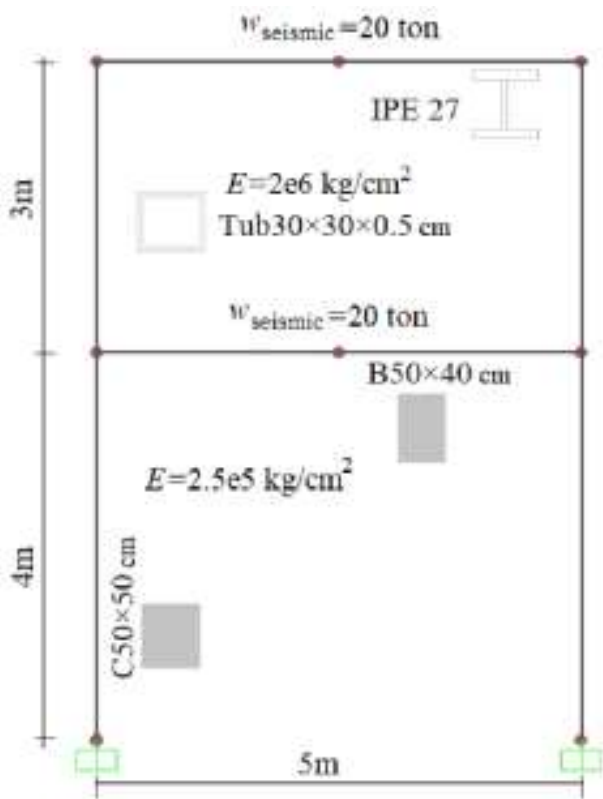

Fig. 3. Configuration of the mixed 2-story building composed of the upper MRF steel and the lower MRF concrete structures

Table 1. Characteristics of the lower and upper parts of the mixed 2-story structure.

\begin{tabular}{ccc}
\hline & Story stiffness, $k($ ton $/ \mathrm{m})$ & Seismic weight of the story, $w$ (ton) \\
\hline Lower concrete structure & 3014.389 & 20 \\
\hline Upper steel structure & 812.324 & 20 \\
\hline
\end{tabular}

Table 2. The fundamental period and frequency of the mixed 2-story structure and the parameters needed.

\begin{tabular}{ccccccccccccc}
\hline$N$ & $n_{1}$ & $n_{2}$ & $\begin{array}{c}m_{1} \\
\left.\text { (ton. } \mathrm{s}^{2} / \mathrm{m}\right)\end{array}$ & $\begin{array}{c}m_{2} \\
\left(\text { ton. } \mathrm{s}^{2} / \mathrm{m}\right)\end{array}$ & $\begin{array}{c}k_{l} \\
(\mathrm{ton} / \mathrm{m})\end{array}$ & $\begin{array}{c}k_{2} \\
(\mathrm{ton} / \mathrm{m})\end{array}$ & $\begin{array}{c}\Delta_{\mathbf{1}} \\
(\mathrm{cm})\end{array}$ & $\begin{array}{c}\Delta_{\mathbf{2}} \\
(\mathrm{cm})\end{array}$ & $\begin{array}{c}\boldsymbol{\omega} \\
(\mathrm{rad} / \mathrm{s})\end{array}$ & $\begin{array}{c}T_{c} \\
(\mathrm{~s})\end{array}$ & $\begin{array}{c}T_{\text {num }} \\
(\mathrm{s})\end{array}$ & $\begin{array}{c}\text { Error } \\
(\%)\end{array}$ \\
\hline 2 & 1 & 1 & 2.040 & 2.040 & 3014.389 & 812.324 & 1.33 & 3.8 & 17.643 & 0.356 & 0.364 & 2.184 \\
\hline
\end{tabular}

\subsection{A mixed 7-story structure composed of the upper CBF Steel and lower MRF concrete structures}

In the second example, it is assumed that a five-story CBF steel structure is constructed on a two-story MRF concrete structure, as shown in Fig. 4. Axial and shear deformations of the beams and columns, and the influence of the axial force on the stiffness of the columns in the lower MRF and the upper CBF structures are neglected. The characteristics of the lower and upper parts of this mixed structure are provided in Table 3. The fundamental period and frequency of the mixed structure resulting from the proposed formula and from the eigenvalue analysis of the numerical model as well as the necessary parameters are given in Table 4. The calculation of the stiffness of each story in the lower MRF structure was 
described in the preceding example. The stiffness of each story in the CBF part of the mixed structure is calculated by the famous formula, $\left(\sum\left\{(A \cdot E / L) \cdot \cos ^{2}(\alpha)\right\}\right)$, in which $E$ is the modulus of elasticity; $A$ is the cross section area of the bracing member; $L$ is the length of the bracing element; and $\alpha$ is the angle between the bracing member and beam.

Table 4 illustrates that there is a good agreement between the fundamental periods obtained from the proposed formula and the eigenvalue analysis of the numerical model of the mixed 7-story building structure. It is noted that the error in the fundamental period of the structure obtained from the proposed formula amounts to $2.13 \%$.

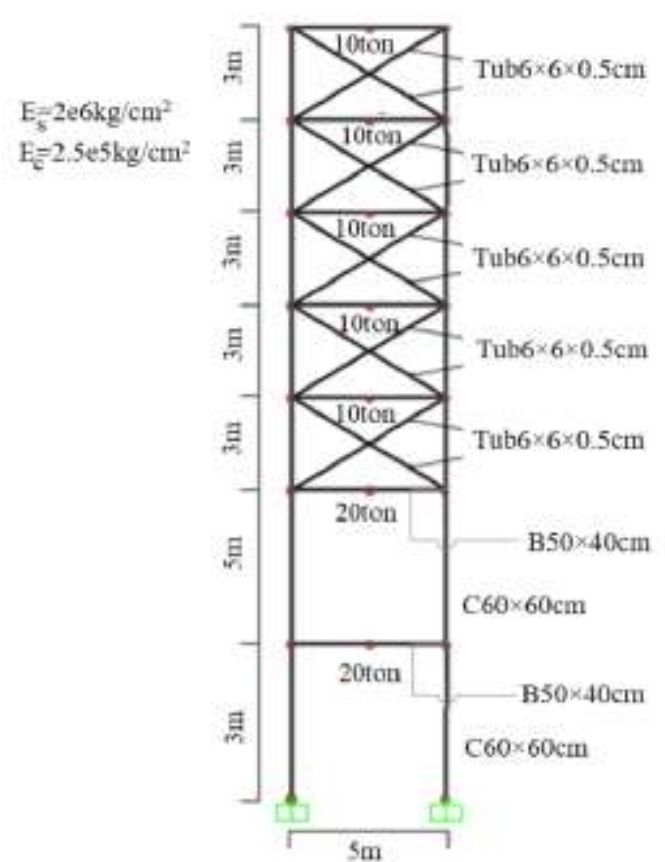

A mixed 7-story building

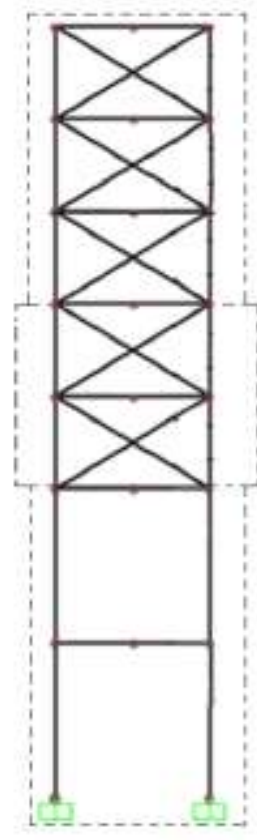

$n_{3}=3, k_{1}=5548.484$ (ton $\left./ \mathrm{m}\right), w_{3}=10$ (ton) $\Delta_{1}=11.693(\mathrm{~cm})$

$n_{2}=2, k_{2}=5548.484(\mathrm{ton} / \mathrm{m}), w_{2}=10$ (ton) $\Delta_{1}=11.332(\mathrm{~cm})$

$n_{1}=2, k_{1}=1647.727(\operatorname{ton} / \mathrm{m}), w_{1}=20($ ton $)$ $\Delta_{1}=9.71(\mathrm{~cm})$

Fig. 4. Configuration of the mixed 7-story building composed of the upper 5-story CBF steel structure and the lower 2-story MRF concrete structure.

Table 3. Characteristics of the lower and upper parts of the mixed 7-story structure.

\begin{tabular}{cccccc}
\hline & $\begin{array}{c}\text { Story } \\
\text { height, } \\
H(\mathrm{~m})\end{array}$ & $\begin{array}{c}\text { Type of seismic resisting } \\
\text { system }\end{array}$ & $\begin{array}{c}\text { Young's } \\
\text { modulus, } \\
E\left(\mathrm{~kg} / \mathrm{cm}^{2}\right)\end{array}$ & $\begin{array}{c}\text { Story } \\
\text { stiffness, } \\
k(\text { ton/m) }\end{array}$ & $\begin{array}{c}\text { Seismic weight of the } \\
\text { story, } \\
w(\text { ton })\end{array}$ \\
\hline $\begin{array}{c}\text { Lower concrete } \\
\text { structure }\end{array}$ & 5 & MRF & 250000 & 1648 & 20 \\
\hline Upper steel structure & 3 & CBF & 2000000 & 5549 & 10 \\
\hline
\end{tabular}


Table 4. The fundamental period and frequency of the mixed 7-story structure and the parameters needed.

\begin{tabular}{ccccccccccccccc}
\hline$N$ & $n_{1}$ & $n_{2}$ & $n_{3}$ & $\begin{array}{c}m_{1} \\
\left(\text { ton. } \mathrm{s}^{2} / \mathrm{m}\right)\end{array}$ & $\begin{array}{c}m_{2} \& m_{3} \\
\left(\text { ton. } \mathrm{s}^{2} / \mathrm{m}\right)\end{array}$ & $\begin{array}{c}k_{1} \\
(\mathrm{ton} / \mathrm{m})\end{array}$ & $\begin{array}{c}k_{2} \& k_{3} \\
(\mathrm{ton} / \mathrm{m})\end{array}$ & $\begin{array}{c}\Delta_{\mathbf{1}} \\
(\mathrm{cm})\end{array}$ & $\begin{array}{c}\Delta_{2} \\
(\mathrm{~cm})\end{array}$ & $\begin{array}{c}\Delta_{3} \\
(\mathrm{~cm})\end{array}$ & $\begin{array}{c}\boldsymbol{\omega} \\
(\mathrm{rad} / \mathrm{s})\end{array}$ & $\begin{array}{c}T_{c} \\
(s)\end{array}$ & $\begin{array}{c}T_{\text {num }} \\
(\mathrm{s})\end{array}$ & $\begin{array}{c}\text { Error } \\
(\%)\end{array}$ \\
\hline 7 & 2 & 2 & 3 & 2.04 & 1.02 & 1648 & 5549 & 9.71 & 11.33 & 11.7 & 9.58 & 0.656 & 0.67 & 2.13 \\
\hline
\end{tabular}

\subsection{Various mixed structures with different seismic characteristics along the height}

Herein, 11 mixed structures with different seismic characteristics along the height are studied. The total number of stories of the mixed structures, $N$, the number of stories of the $i$-th part, $n_{i}$, the seismic mass of the $i$-th part, $m i$, the lateral stiffness of the $i$-th part, $k_{i}$, and the results are presented in Table 5. It should be noted that $\sum_{i=1}^{n} n_{i}=N$ and $\mathrm{n}$ is the number of all parts taken into account. The results provide evidence that the proposed formula is able to accurately determine the fundamental period of the mixed structures. The largest error in the fundamental period of these structures derived from the proposed formula is less than $10 \%$ as compared to that from the eigenvalue analysis of the numerical model of the frames.

It is interesting to note that the fundamental period of the examined mixed structures, which was determined by means of the proposed formula, is lower than that from the eigenvalue analysis of the numerical model, since the proposed formula has been obtained on the basis of the Rayleigh's method for which the fundamental frequencies are always larger than the true frequencies. As a result, the proposed formula may result in a conservative design in practice to a small degree. 
Table 5. The fundamental period and frequency of the various mixed structures with different seismic characteristics along the height as well as the necessary parameters.

\begin{tabular}{|c|c|c|c|c|c|c|c|c|c|c|c|}
\hline No of Structure & 1 & 2 & 3 & 4 & 5 & 6 & 7 & 8 & 9 & 10 & 11 \\
\hline$n^{\mathrm{a}}$ & 3 & 3 & 3 & 3 & 4 & 4 & 5 & 5 & 6 & 6 & 6 \\
\hline$N^{\mathrm{b}}$ & 6 & 7 & 8 & 9 & 10 & 12 & 14 & 15 & 16 & 18 & 20 \\
\hline$n_{1}{ }^{\mathrm{c}}$ & 2 & 2 & 2 & 3 & 2 & 3 & 3 & 3 & 3 & 3 & 3 \\
\hline$n_{2}{ }^{\mathrm{c}}$ & 2 & 2 & 3 & 3 & 2 & 3 & 3 & 3 & 3 & 3 & 3 \\
\hline$n_{3}{ }^{\mathrm{c}}$ & 2 & 3 & 3 & 3 & 3 & 3 & 3 & 3 & 3 & 3 & 3 \\
\hline$n_{4}{ }^{\mathrm{c}}$ & & & & & 3 & 3 & 3 & 3 & 3 & 3 & 3 \\
\hline$n_{5}{ }^{\mathrm{c}}$ & & & & & & & 2 & 3 & 2 & 3 & 3 \\
\hline$n_{6}{ }^{\mathrm{c}}$ & & & & & & & & & 2 & 3 & 5 \\
\hline (ton. $\mathrm{s}^{2} / \mathrm{m}$ ) & 16.32 & 22.95 & 22.95 & 22.95 & 22.95 & 22.95 & 22.95 & 22.95 & 22.95 & 22.95 & 22.95 \\
\hline (ton. $\left.\mathrm{s}^{2} / \mathrm{m}\right)$ & 16.32 & 16.32 & 16.32 & 16.32 & 16.32 & 16.32 & 16.32 & 16.32 & 22.95 & 22.95 & 22.95 \\
\hline (ton.s ${ }^{2} / m$ ) & 16.32 & 16.32 & 16.32 & 16.32 & 16.32 & 16.32 & 16.32 & 16.32 & 16.32 & 16.32 & 16.32 \\
\hline (ton. $\mathrm{s}^{2} / \mathrm{m}$ ) & & & & & 16.32 & 16.32 & 16.32 & 16.32 & 16.32 & 16.32 & 16.32 \\
\hline (ton. $\mathrm{s}^{2} / \mathrm{m}$ ) & & & & & & & 16.32 & 16.32 & 16.32 & 16.32 & 16.32 \\
\hline (ton.s $\left.{ }^{2} / \mathrm{m}\right)$ & & & & & & & & & 16.32 & 16.32 & 16.32 \\
\hline (ton/m) & 36000 & 47000 & 52000 & 52000 & 64000 & 88000 & 88000 & 88000 & 88000 & 88000 & 88000 \\
\hline (ton/m) & 25000 & 25000 & 47000 & 47000 & 52000 & 52000 & 52000 & 52000 & 64000 & 64000 & 64000 \\
\hline (ton/m) & 20000 & 20000 & 25000 & 25000 & 47000 & 47000 & 47000 & 47000 & 52000 & 52000 & 52000 \\
\hline (ton/m) & & & & & 25000 & 25000 & 31000 & 31000 & 47000 & 47000 & 47000 \\
\hline (ton/m) & & & & & & & 25000 & 25000 & 31000 & 31000 & 31000 \\
\hline (ton/m) & & & & & & & & & 25000 & 25000 & 25000 \\
\hline$(\mathrm{cm})$ & 4.889 & 4.84 & 4.99 & 8.135 & 5.055 & 6.443 & 7.534 & 8.08 & 9.29 & 10.38 & 11.47 \\
\hline$(\mathrm{cm})$ & 9.369 & 10.6 & 10.1 & 13.24 & 9.67 & 13.83 & 16.76 & 18.23 & 18.9 & 21.49 & 24.08 \\
\hline$(\mathrm{cm})$ & 10.57 & 12.2 & 11.38 & 14.52 & 14.78 & 18.93 & 23.91 & 26.4 & 27.21 & 31.64 & 36.08 \\
\hline$(\mathrm{cm})$ & & & & & 18.62 & 22.77 & 28.04 & 32.08 & 33.33 & 39.81 & 46.29 \\
\hline$\Delta_{5} \quad(\mathrm{~cm})$ & & & & & & & 29.96 & 35.92 & 36.95 & 47.56 & 57.13 \\
\hline$\Delta_{6} \quad(\mathrm{~cm})$ & & & & & & & & & 38.87 & 51.4 & 66.73 \\
\hline $\boldsymbol{\omega} \quad(\mathrm{rad} / \mathrm{s})$ & 10.44 & 9.935 & 10.24 & 8.956 & 8.417 & 7.498 & 6.399 & 5.945 & 5.679 & 5.045 & 4.545 \\
\hline$T_{c}{ }^{\mathrm{d}} \quad(\mathrm{s})$ & 0.602 & 0.632 & 0.614 & 0.702 & 0.746 & 0.838 & 0.982 & 1.057 & 1.106 & 1.245 & 1.382 \\
\hline$T_{\text {num }}{ }^{\mathrm{d}}(\mathrm{s})$ & 0.614 & 0.695 & 0.655 & 0.723 & 0.757 & 0.917 & 1.07 & 1.16 & 1.178 & 1.336 & 1.506 \\
\hline Error (\%) & 2.025 & 9 & 6.387 & 2.967 & 1.381 & 8.595 & 8.235 & 8.883 & 6.106 & 6.802 & 8.232 \\
\hline
\end{tabular}

\section{Conclusions}

ASCE/SEI 41-17 (2017) permits the use of an approximate method to determine the fundamental period of vibration of structures, but no simplified equation has been previously proposed for the determination of the fundamental period of mixed structures with vertical combination of different seismic resistant systems. In this study, by using the Rayleigh's method, a simplified and straightforward formula was proposed to compute the fundamental period of vibration of this type of structures. This formula was verified by the analytical method (i.e. the eigenvalue analysis of the numerical models). The proposed formula can be used in the seismic evaluation process of existing buildings as well as in the design process of new ones. 
The results indicate that the proposed formula gives accurately the fundamental period of mixed structures. The maximum and average errors in the fundamental period of the examined structures resulting from the proposed formula are less than $10 \%$ and $6 \%$, respectively, as compared to that from the eigenvalue analysis of the numerical model. Furthermore, the fundamental period of the examined mixed structures, obtained from the proposed formula, is always lower than that from the eigenvalue analysis of the numerical model. Consequently, the proposed formula may lead, to some extent, to a conservative design for practical realistic mixed buildings with a combination of different seismic resistant systems along the height.

\section{References}

Ahmed N. Mohamed, Khaled F. El Kashif, Hamed M. Salem. (2019). “An Investigation of the Fundamental Period of Vibration for Moment Resisting Concrete Frames.” Journal of Civil Engineering Journal, 5(12), 26262642.

Alguhane T, Fayed M, Hussin A, Ismail A. (2016). "Simplified Equations For Estimating The Period Of Vibration Of Ksa Existing Building Using Ambient vibration testing.” Journal of Multidisciplinary Engineering Science and Technology, 3(3), 4335-4343.

Amanat K, Hoque E. (2006). "A rationale for determining the natural period of RC building frames having infill.” Journal of Engineering Structures, 28(4), 495-502.

ASCE (American Society of Civil Engineers). (2016). "Minimum design loads and Associated Criteria for buildings and other structures.” ASCE standard No. 7-16, Reston.

ASCE (American Society of Civil Engineers). (2017). "Seismic evaluation and retrofit of existing buildings." ASCE standard No. 41-17, Reston.

ATC (1978)."Tentative provisions for the development of seismic regulations for buildings.”, ATC3-06. Palo Alto, (CA): Applied Technology Council. 
Barghi, M. and Azadbakht, M. (2011). "Evaluating the effect of masonry infills on natural period of buildings with moment-resisting frame.” Journal of The Structural Design of Tall and Special Buildings, 20(6), 649-660.

Chopra, A.K. (2012). Dynamics of Structures. Theory and Applications to Earthquake Engineering, Fourth Edition, Prentice Hall, Englewood Cliffs, NJ.

Crowley H, Pinho R. (2006). "Simplified equation for estimating the period of vibration of existing buildings." First European Conference on Earthquake Engineering and Seismology, 1122, 3-8.

Crowley H, Pinho R. (2010). "Revisiting Eurocode 8 formulae for periods of vibration and their employment in linear seismic analysis.” Journal of Earthquake Engineering \& Structural Dynamics, 39, 223-235.

Ditommaso R, Vona M, Gallipoli M, Mucciarelli M. (2013). "Evaluation and considerations about fundamental periods of damaged reinforced concrete buildings", Natural Hazard and Earth System Science,13(7), 19031912.

Eurocode 8 (2004). “Design of Structures for Earthquake Resistance.”, EN1998-1, Belgium.

Gallipoli M, Mucciarelli M, Šket-Motnikar B., Zupanćić P, Gosar A, Prevolnik S, et al. (2010). "Empirical estimates of dynamic parameters on a large set of European buildings.” Bull Earthquake Eng, 8(3), 593-607.

Goel RK, Chopra AK. (1997). "Period formulas for moment-resisting frame buildings", Journal of Structural Engineering (ASCE), 123(11),1454-1461.

Georgoussis G, Tsompanos A, Makarios T. (2015). “Approximate seismic analysis of multi-story buildings with mass and stiffness irregularities.” Procedia Engineering, 125, 959 - 966.

Guler K, Yuksel E, Kocak A. (2008). "Estimation of the fundamental vibration period of existing RC buildings in Turkey utilizing ambient vibration records", Journal of Engineering Structural,12(S2), 140-50.

Günaydın E. and Topkaya C. (2013). "Fundamental periods of steel concentrically braced frames designed to Eurocode 8." Journal of Earthquake Engineering \& Structural Dynamics, 42, 1415-1433.

Hatzigeorgiou, G.D. and Kanapitsas, G. (2013). "Evaluation of fundamental period of low-rise and mid-rise reinforced concrete buildings.” Journal of Earthquake Engineering \& Structural Dynamics., 42, 1599-1616.

ICBO (International Conference of Building Offcials). (1997). “Uniform Building Code.”, Whittier, CA. 
IBC (International Building Code). (2020). “2021 International Building Code.” 4051 Flossmoor Road, Country Club Hills.

Kown, O.S. and Kim, E.S. (2010). "Evaluation of building period formulas for seismic design." Journal of Earthquake Engineering \& Structural Dynamics, 39(14), 1569-1583.

Kaplan, O., Guney, Y., and Dogangun, A. (2021). “A period-height relationship for newly constructed mid-rise reinforced concrete buildings in Turkey.” Journal of Engineering Structural., 232, 111807.

Kuşyılmaz A, TopkayaC. (2014). "Fundamental periods of steel eccentrically braced frames." Journal of The Structural Design of Tall and Special Buildings, 24(2), 114-123.

Lee L, Chang K, Chun Y. (2000) "Experimental formula for the fundamental period of RC buildings with shearwall dominant systems.” Journal of The Structural Design of Tall Buildings, 9, 295-307.

Michel C, Gu'eguen P, Lestuzzi P, Bard P-Y. (2010). “Comparison between seismic vulnerability models and experimental dynamic properties of existing buildings in France.” Bull Earthquake Eng, 8(6), 1295-307.

Nassani, DE. (2014). "A Simple Model for Calculating the Fundamental Period of Vibration in Steel Structures." Journal of APCBEE Procedia, 9, 339 - 346.

Navarro M, Vidal F, Enomoto T, Alcal’a FJ, García-Jerez A, S'anchez FJ, Abeki N. (2007). “Analysis of the weightiness of site effects on reinforced concrete $(\mathrm{RC})$ building seismic behavior: The Adra town example (SE Spain).” Journal of Earthquake Engineering \& Structural Dynamics, 36(10), 1363-83.

NBCC (2015) “National building code of Canada 2015.”, Fourteenth Edition, Canada.

NEHRP (the National Earthquake Hazards Reduction Program). (2021). "The 2020 NEHRP Recommended Seismic Provisions for New Buildings and Other Structures.” FEMA P-2082, Building Seismic Safety Council, Washington (D.C.).

Oliveira C, Navarro M. (2010). "Fundamental periods of vibration of RC buildings in Portugal from in-situ experimental and numerical techniques.” Bull Earthquake Eng, 8(3), 609-42.

Panagiotis G. Asteris, Constantinos C. Repapis and Liborio Cavaleri. (2015). "On the fundamental period of infilled RC frame buildings.” Journal of Structural Engineering and Mechanics, 54(6), 1175-1200. 
Paultre, P. (2011). “Dynamics of Structures.” ISTE Ltd and John Wiley \& Sons, Inc.

Pan T-C., Goh KS., Megawati K., (2014). "Empirical relationships between natural vibration period and height of buildings in Singapore.” Journal of Earthquake Engineering \& Structural Dynamics, 43 (3), 449-65.

Ricci P, Verderame G, Manfredi G. (2011). “Analytical investigation of elastic period of infilled RC MRF buildings." Journal of Engineering Structures, 33(2), 308-319.

Salameh C, Guillier B, Harb J, Cornou C, Bard P-Y, Voisin C, Mariscal A. (2016) "Seismic response of Beirut (Lebanon) buildings: instrumental results from ambient vibrations.” Bull Earthq Eng, 14(10), 2705-30.

Salama M. (2015). "Estimation of period of vibration for concrete moment-resisting frame buildings.” Journal of Housing and Building National Research Center, 11(1), 16-21.

Sarkar P, Prasad A.M, Menon D. (2010). "Vertical geometric irregularity in stepped building frames.” Journal of Engineering Structures, 32, 2175-2182.

Tremblay, R. (2005). "Fundamental periods of vibration of braced steel frames for seismic design." Journal of Earthquake Spectra, 21(3), 833-860.

UBC (Uniform Building Code), (1997). “International Conference of Building Officials.”, Whittier, CA.

Young K, Adeli H. (2014a). "Fundamental period of irregular moment-resisting steel frame structures", Journal of the Structural Design of Tall and Special Buildings, 23(15), 1141-1157.

Young K, Adeli H. (2014b). "Fundamental period of irregular concentrically braced steel frame structures", Journal of the Structural Design of Tall and Special Buildings, 23, 1211-1224.

\section{Appendix A}

In this appendix, the process of deriving Eqs. (3b) and (3c) is presented. First of all, the calculation of the relative displacement in the $i$-th part, $\delta_{i}$, with the assumption of the fixedbase condition at the bottom of the part under inertia forces, is carried out. In Fig. A1, the $i$-th 
part of the structure with $n_{i}$ stories under inertia forces is shown. The relative displacement of each story in the $i$-th part is calculated as follows:

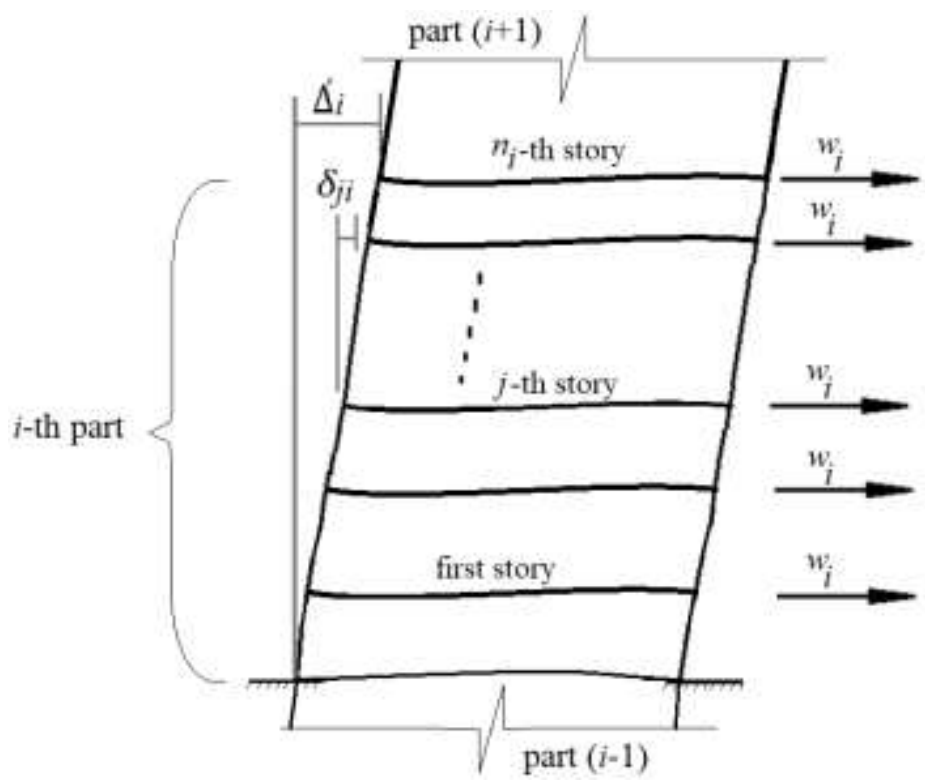

Fig. A1. The $i$-th part of the mixed structure with the assumption of the fixed base condition at the bottom of the part under inertia forces (The part has $n_{i}$ stories and the weight and stiffness of all stories of the part are dented by $w_{i}$ and $k_{i}$, respectively).

$\delta_{n_{i}}=\frac{w_{i}}{k_{i}} \quad$ at story $n_{i}$

$\delta_{\left(n_{i}-1\right)_{i}}=2 \frac{w_{i}}{k_{i}} \quad$ at story $\left(n_{i}-1\right)$

$\delta_{1_{i}}=n_{i} \frac{w_{i}}{k_{i}} \quad$ at the first story

After the calculation of the relative displacement of each story at the $i$-th part of the mixed structure, the maximum displacement of this part due to the inertia forces in the part, $\Delta^{\prime}{ }_{i}$, is computed by: 
$\Delta_{i}^{\prime}=\sum_{j=1}^{n_{i}} \delta_{j}=\left(1+2+\cdots+n_{i}\right) \frac{w_{i}}{k_{i}}=\frac{\left(1+n_{i}\right)}{2} n_{i} \frac{w_{i}}{k_{i}}$

The parts above the $i$-th part of the mixed structure influence the maximum displacement of this part. Therefore, the effect of parts above the $i$-th part (i.e. $j=i+1, \ldots, n)$ on the maximum displacement of the $i$-th part should be considered. The weight and stiffness of each story in the $j$-th part are denoted by $w_{j}$ and $k_{j}$, respectively. The maximum displacement of the $i$-th part due to the inertia forces of the $j$-th part $(j=i+1, \ldots, n)$ with $n_{j}$ stories, $e_{j}$, is computed by:

$e_{j}=n_{i} \frac{n_{j} w_{j}}{k_{i}} \quad j=i+1, \ldots, n$

The sum of the maximum displacements of the $i$-th part due to the inertia forces of the $j$-th part obtained in Eq. (A5) is derived as follows:

$\Delta^{\prime \prime}{ }_{i}=\frac{n_{i}}{k_{i}} \sum_{j=i+1}^{n} n_{j} w_{j} \quad i=1, \ldots, n-1$ 